Jurnal Sistem Informasi (Journal of Information Systems). 2/10 (2014), 63-69

DOI: http://dx.doi.org/10.21609/jsi.v10i2.386

\title{
ANALISIS KUALITAS APLIKASI UJIAN ONLINE BERBASIS WEB PADA PERUM PERUMNAS
}

\author{
Hoga Saragih $^{1}$ dan Siti Safariana ${ }^{2}$ \\ ${ }^{1}$ Fakultas Teknik dan Ilmu Komputer, Universitas Bakrie \\ Kampus Kuningan, Kawasan Epicentrum, Jl. H.R. Rasuna Said Kav. C-22 Jakarta 12920. \\ ${ }^{2}$ Program Studi Magister Teknik Informatika, Universitas Bina Nusantara
}

Jl. K.H. Syahdan No.9, Palmerah, Jakarta, 11480 hoga.saragih@bakrie.ac.id, safariana3@gmail.com

\begin{abstract}
Human resources Department utilizing information and communication technology development to further improve the quality of the company's employees. One of them by developing a Web-Based Employee Application Exam. Department of Human resources at Housing realize that the role of employees determines the success or failure of the company to meet its goals. With a good selection process, employees received will be qualified so that coaching, development, and setting employees becomes easier. This research evaluates the quality of an online exam website based on the Web-site Quality Evaluation Method. The analysis results indicate that the website quality is not satisfactory. Thus, the department needs to re-design development of a website prototype using the Spiral Development Method.
\end{abstract}

Keywords: quality application, website evaluation quality method, web based exam

\begin{abstract}
Abstrak
Departemen Sumber Daya Manusia memanfaatkan perkembangan teknologi informasi dan komunikasi untuk semakin meningkatkan kualitas karyawan perusahaan. Salah satunya dengan cara mengembangkan Aplikasi Ujian Karyawan Berbasis Web. Departemen SDM di Perumnas menyadari bahwa Peran karyawan sangat menentukan berhasil tidaknya perusahaan mencapai tujuannya. Dengan proses pelaksanaan seleksi yang baik, karyawan yang diterima akan lebih qualified sehingga pembinaan, pengembangan, dan pengaturan karyawan menjadi lebih mudah. Pada penelitian ini akan mengevaluasi kualitas website ujian online berdasarkan Web-site Quality Evaluation Method. Hasil analisa menunjukkan kualitas website yang tidak memuaskan, sehingga perlu adanya perancangan pengembangan website menggunakan prototype dengan Metode Pengembangan Spiral.
\end{abstract}

Kata Kunci: kualitas aplikasi, metode evaluasi kualitas website, ujian berbasis web

\section{Pendahuluan}

Seiring perkembangan teknologi informasi yang selalu menciptakan inovasi baru, terutama teknologi Internet yang berperan dalam mempermudah akses dan meningkatkan kecepatan serta mengurangi biaya penggunaan. Sebagai media yang semakin kuat, interaktif, dan dinamis untuk memberikan informasi, World Wide Web (WWW) dalam kombinasi dengan teknologi informasi (misalnya LAN, WAN, Internet, dll) telah menemukan banyak aplikasi. Salah satu aplikasi populer telah digunakan pendidikan, seperti berbasis Web, jarak, didistribusikan atau pembelajaran online bahkan ujian online [1].

Berbagai pihak berusaha dan bersaing untuk menjadi yang terdepan dalam penguasaan teknologi informasi dan komunikasi, sehingga saat ini banyak teknologi yang berkembang. Pihak-pihak tersebut mengutamakan perkembangan teknologi komunikasi jarak jauh dan kemudahan dalam mengakses informasi. Software yang digunakan da- lam berbagai aplikasi semakin luas area cakupan-nya, dan operasi yang baik merupakan hal penting untuk keberhasilan bisnis [2]. Ketika pertama kali digunakan dalam organisasi besar, menunjukkan bahwa software yang digunakan dalam Human resource telah digunakan dalam berbagai jenis organisasi untuk semua ukuran [3]. Berbagai aplikasi dapat diciptakan untuk membantu proses kerja Departemen Sumber Daya Manusia (SDM) seperti aplikasi informasi karyawan, survei karyawan hingga rekrutmen karyawan.

Departemen SDM di Perumnas menyadari bahwa Peran karyawan sangat menentukan berhasil tidaknya perusahaan mencapai tujuannya. Dengan proses pelaksanaan seleksi yang baik, karyawan yang diterima akan lebih terkualifikasi sehingga pembinaan, pengembangan, dan pengaturan karyawan menjadi lebih mudah. Penilaian terhadap calon karyawan merupakan bagian yang amat penting. Evaluasi dapat memberi gambaran tentang kemampuan seseorang yang melakukan proses ujian. Penilaian secara manual dengan instrumen evaluasi 


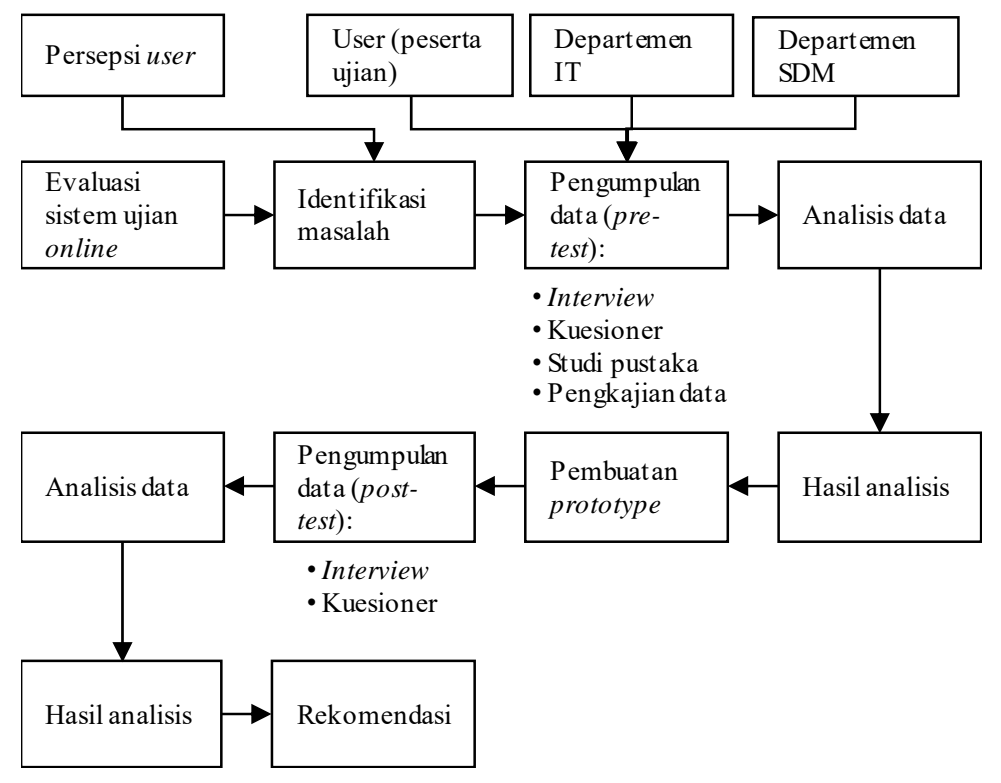

Gambar 1. Alur Kerja Penelitian

memiliki banyak kelemahan. Pertama, evaluasi manual memerlukan waktu dan biaya yang cukup banyak untuk memproduksi instrumennya. Kedua, pemilihan butir tes dari bank soal cukup merepotkan, baik dalam pemilihan maupun dalam memproduksinya. Ketiga, proses pemeriksaan evaluasi dengan instrumen tercetak cukup rumit, sehingga memerlukan waktu banyak. Keempat, proses pengolahan skor yang rumit dan memerlukan banyak waktu. Kelima, secara psikologis evaluasi manual sering menimbulkan kecemasan pada peserta tes. Pengawas yang berada di sekitar mereka, kondisi peserta tes yang lain, serta kondisi lingkungan sekitar sering membuat peserta tes merasa cemas [4].

Perum Perumnas harus dapat menyikapi dan mengikuti kebutuhan teknologi informasi yang semakin berkembang pesat. Dalam hal ini pemanfaatan teknologi informasi diperlukan agar Perum Perumnas dapat menghadapi persaingan dalam dunia bisnis. Salah satu cara yang dilakukan Perum Perumnas untuk dapat bersaing dalam dunia bisnis adalah dengan tidak hanya memanfaatkan metode ujian tradisional saja melainkan dengan menggunakan konsep ujian berbasis web. Dengan memanfaatkan teknologi internet, mereka dapat memperoleh data yang diperlukan dengan waktu yang lebih cepat dan biaya yang lebih murah disbandingkan tanpa menggunakan internet. Untuk itu, Perumnas mencoba untuk menerapkan konsep online untuk menggantikan konsep manual atau tradisional yang digunakan sebelumnya.

Konsep online yang diterapkan Perumnas merupakan penilaian yang dilakukan untuk mengukur tingkat kesuksesan atau pencapaian suatu pembelajaran saat akhir proses pembelajaran itu sen- diri. Sebelum menerapkan teknologi ini, perusahaan harus menghabiskan waktu yang lebih lama dan biaya yang besar setiap kali mengadakan ujian bagi para karyawan yang akan naik golongan atau jabatan. Oleh karena itu, perusahaan menerapkan sistem baru berbasiskan aplikasi web yang diberi nama Perumnas Assessment Online Assisstence (PAOLA).

Dengan sistem online ini, perusahaan dapat memperoleh informasi yang dibutuhkan dalam waktu yang lebih cepat dibandingkan dengan sistem tradisional. Informasi yang diperoleh, dapat diolah menjadi data yang berguna bagi perusahaan. Sistem PAOLA diharapkan dapat menjadi sebuah aplikasi yang efektif dan dapat dihandalkan untuk menghasilkan data-data dari proses ujian kenaikan golongan. Desain dibuat sesederhana mungkin agar memudahkan peserta ujian mengakses aplikasi ini. Performa aplikasi yang baik dapat membantu peserta ujian agar lebih efektif dalam mengerjakan soal [5].

Aplikasi untuk melakukan seleksi karyawan tersebut telah digunakan semenjak 2012. Pihak Departemen SDM Perumnas sering mendapat keluhan dari para peserta ujian mengenai aplikasi yang mereka gunakan ketika melaksanakan ujian. Selain tampilan antarmuka yang kurang memadai, lambatnya performa dari aplikasi yang berbasiskan web tersebut merupakan keluhan yang sering disampaikan kepada pihak SDM.

Masalah-masalah yang banyak dihadapi organisasi terkait aplikasi dan bagaimana pentingnya melakukan evaluasi aplikasi ini. Selain itu, karena konteksnya adalah melakukan evaluasi kualitas, berbagai kerangka evaluasi aplikasi yang sudah di- 
TABEL 1

PemetaAn Hasil Kuesioner

\begin{tabular}{lllll}
\hline Variabel & $\begin{array}{l}\text { Sangat } \\
\text { Setuju }\end{array}$ & Setuju & $\begin{array}{l}\text { Tidak } \\
\text { Setuju }\end{array}$ & $\begin{array}{l}\text { Sangat } \\
\text { Tidak } \\
\text { Setuju }\end{array}$ \\
\hline $\begin{array}{l}\text { Interface } \\
\text { Attractiveness }\end{array}$ & $3 \%$ & $10 \%$ & $46 \%$ & $41 \%$ \\
Operability & $10 \%$ & $12 \%$ & $31 \%$ & $47 \%$ \\
Understandability & $4 \%$ & $15 \%$ & $30 \%$ & $51 \%$ \\
Navigation & $29 \%$ & $47 \%$ & $17 \%$ & $7 \%$ \\
Suitability & $4 \%$ & $18 \%$ & $29 \%$ & $49 \%$ \\
Availability & $2 \%$ & $9 \%$ & $33 \%$ & $56 \%$ \\
Accessibility & $17 \%$ & $24 \%$ & $27 \%$ & $32 \%$ \\
Time Behavior & $\underline{3 \%}$ & $\underline{13 \%}$ & $\underline{29 \%}$ & $\underline{55 \%}$ \\
\hline
\end{tabular}

kembangkan untuk melakukan seleksi karyawan.

\section{Kerangka Penilaian Kualitas Aplikasi}

Luis Olsina et al. melakukan penelitian terhadap atribut kualitas website yang ditujukan untuk website akademik. Penelitian mengambil sudut pandang teknis and mengidentifikasikan faktor-faktor yang terkait. Dengan menggunakan Website Quality Evaluation Method (WebQEM) dan softwarenya, penelitian dilakukan untuk menilai kualitas website dan aplikasinya. Mengukur indikator kualitas dapat membantu pihak yang berkepentingan untuk memahami dan meningkatkan kualitas website. Survei kuantitatif dan evaluasi website dengan domain tertentu seperti domain website e-commerce, domain website museum, domain website akademik dan sebagainya, membantu evaluasi usability dengan kuesioner bersifat subjektif pengguna, suatu strategi dengan kekuatan dan kelemahan masingmasing [6].

Doaa Nabil menetapkan faktor-faktor yang menilai kualitas WBA, mengidentifikasi fak-torfaktor kualitas utama dan sub faktor yang berdasarkan pandangan WBA dan penggunaan. Pertama, penelitian ini menyarankan suatu model konseptual untuk mengidentifikasi pandangan WBA yang berbeda dan penggunaan yang berfokus pada pengunjung, pemilik, dan pengembang. kedua; mengidentifikasi dan mengkategorikan faktor kualitas dan sub faktor WBA. Model yang diusulkan diterapkan ISO9126 faktor kualitas dan sub faktor untuk meninjau fitur umum antara WBA dan software, dan kemudian mengusulkan serangkaian faktor kualitas WBA baru yang sesuai dengan karakteristik khusus WBA. Di masa depan, model akan diperpanjang oleh studi eksperimental dan didukung oleh kerangka validasi untuk memberikan beberapa bukti mengenai faktor kualitas disarankan WBA dan sub-faktor [7].

Kavindra Kumar Singh mengemukakan pentingnya kerangka evaluasi web. Ia mengusulkan tiga struktur tingkat, yaitu karakteristik kualitas, kualitas sub-karakteristik dan kriteria terukur (indikator). Di tingkat pertama, kerangka evaluasi web

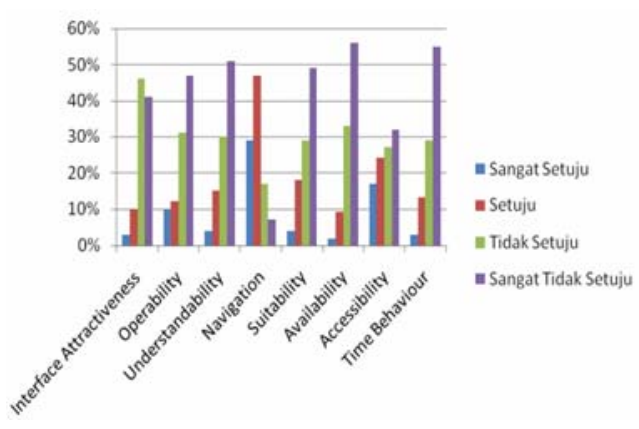

Gambar 2. Grafik hasil kuesioner

mengusulkan lima karakteristik kualitas, yaitu estetika, kemudahan penggunaan, multimedia, konten, serta reputasi. Estetika dan reputasi merupakan bagian utama dari makalah ini. Karakteristik tingkat kedua dipecah menjadi beberapa sub-karakteristik. Setiap sub-karakteristik diwariskan dari kualitas karakteristik. Namun, hanya estetika dan kemudahan penggunaan yang memiliki sub-karakteristik. Sementara multimedia, konten, serta reputasi secara langsung digolongkan ke tingkat ketiga, yaitu indikator terukur [8].

Tsigereda W. Mebrate meneliti beberapa macam model untuk mengevaluasi website. Di antaranya Web-QEM, 2QCV3Q, MiLE, dan MINERVA. Semua model untuk mengevaluasi website bersumber dari ISO-9126. Hasil penelitian yang dilakukan adalah mengajukan framework baru untuk mengevaluasi website. Framework tersebut terdiri dari high level quality factor dan sub-quality factor dan diberi nama WEBUSE method. High level quality yang diajukan adalah content, usability, reliability, efficiency, functionality dan beserta subquality faktornya [9].

\section{Metode}

Metode yang digunakan pada penelitian ini dijelaskan sebagai berikut:

\section{Website Quality Evaluation Method}

Website Quality Evaluation Method (WebQEM) merupakan suatu metode untuk mengevaluasi kualitas dari sebuah aplikasi website. Faktor yang menjadi high level quality ada empat faktor yaitu, usability, functionality, reliability dan efficiency.

Peneliti menggunakan kerangka kerja WebQEM untuk mengevaluasi kualitas aplikasi ujian berbasis web. Dalam penelitian ini akan digunakan kuesioner, pengamatan dan wawancara untuk mengumpulkan data primer. Sedangkan data sekunder didapat dari berbagai buku, jurnal, dan penelitian yang pernah dilakukan terkait dengan evaluasi kua- 


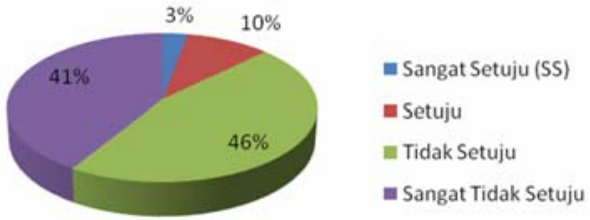

Gambar 3. Grafik interface attractiveness web ujian

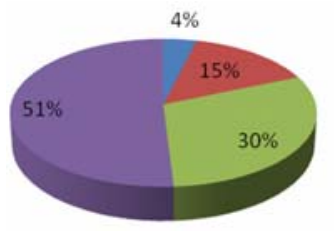

n Sangat Setuju (SS)

= Setuju

= Tidak Setuju

- Sangat Tidak Setuju

Gambar 5. Grafik understandability web ujian

litas website.

Gambar 1 menunjukkan alur kerja penelitian yang dilakukan peneliti. Studi kasus yang dilaku-kan berdasarkan penerapan sistem ujian online di Perumnas. Sistem yang telah digunakan selama dua tahun terakhir dan telah memunculkan beberapa masalah yang telah teridentifikasi baik oleh pengguna maupun administrator. Berdasarkan permasalahan yang terjadi, data pendukung penelitian dikumpulkan melalui beberapa cara seperti studi pustaka, pengkajian data, kuesioner serta wawancara. Sumber yang digunakan untuk memperoleh data-data yang dibutuhkan, yaitu pengguna (peserta ujian), departemen IT dan departemen SDM.

Data yang telah diperoleh dari interview ke pengguna dan administrator, akan digunakan untuk analisis kualitatif. Untuk metode kuantitatif, data akan diambil dalam bentuk kuesioner yang akan dibagikan kepada pengguna yaitu peserta ujian. Data-data untuk analisis tampilan sistem ujian online, akan diambil dari dua departemen di Perumnas yaitu departemen SDM dan departemen IT. Setelah mendapatkan hasil analisis, akan dibuat sebuah prototype yang digunakan sebagai bahan perbandingan dengan sistem ujian online yang sedang berjalan. Setelah prototype selesai dibuat, akan dilakukan pengumpulan data kedua (posttest). User akan diberikan kuesioner mengenai prototype yang telah dibuat. Selanjutnya akan dilakukan analisis kualitatif kedua untuk memproses data posttest, dan akan dilakukan perbandingan hasil pretest dan posttest. Setelah mendapatkan hasil akhir, maka akan dibuat rekomendasi untuk perusahaan.

Kuesioner memuat 4 (empat) high level quality yaitu usability, functionality, reliability dan efficiency. Yang masing-masing memiliki sub menjadi 8 (delapan) sub-variabel yaitu Interface attractiveness, operability, understandability, navigation,

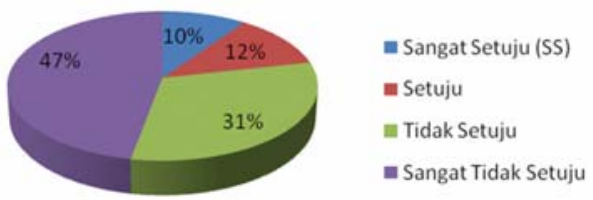

Gambar 4. Grafik operability web ujian

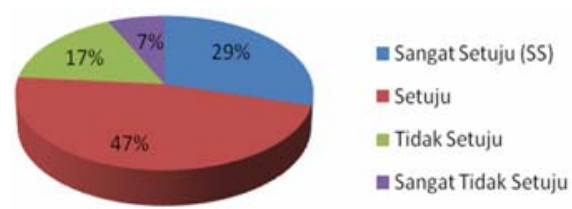

Gambar 6. Grafik navigasi web ujian

suitability, availability, accessibility dan time behaviour. Masing-masing variabel memiliki indikator untuk mendapatkan data mengenai evaluasi kualitas website.

Kuesioner akan dibagikan ke kantor perumnas yang berada di Jabodetabek yaitu Kantor Pusat, Kantor Regional 2 dan Kantor Regional 3. Kuesioner pertama (pretest) akan diberikan pada peserta ujian untuk mendapatkan masalah awal dari kinerja sistem ujian online. Sedangkan kuesioner kedua, diberikan setelah pengguna mencoba prototyping yang telah dibuat. Data-data dari kuesioner evaluasi kinerja sistem ujian online pada perumnas akan diolah lebih lanjut.

Dalam membangun prototipe, peneliti akan menggunakan metode pengembangan spiral karena proses yang cepat dan dapat langsung dievaluasi oleh pengguna. Dengan evaluasi langsung, prototipe dapat menyesuaikan user interface yang sesuai. Interface struktural adalah antarmuka yang menyajikan pengguna dengan struktur pengetahuan, sedangkan antarmuka konseptual menyajikan konsep dan ide-ide utama. Interface yang baik, yang meliputi unsur-unsur struktural dan konseptual, akan lebih efektif untuk belajar daripada hanya satu interface saja [10].

\section{Hasil dan Analisis}

Hasil yang didapatkan dari pengumpulan data kuesioner, peneliti melakukan pemetaan dalam kerangka WebQEM ditampilkan pada Tabel 1 pemetaan hasil kuisioner. Gambar 2 menunjukan grafik batang yang menggambarkan persentase jawaban pengguna untuk setiap variabel WebQEM yang dapat dilihat pada Gambar 2.

Dari hasil kuesioner yang didapat, peneliti melakukan analisa yang akan diuraikan seperti Gambar 3. Gambar 3 menunjukkan grafik Interface 


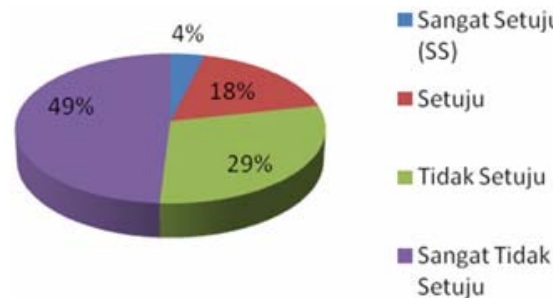

Gambar 7. Grafik suitability web ujian

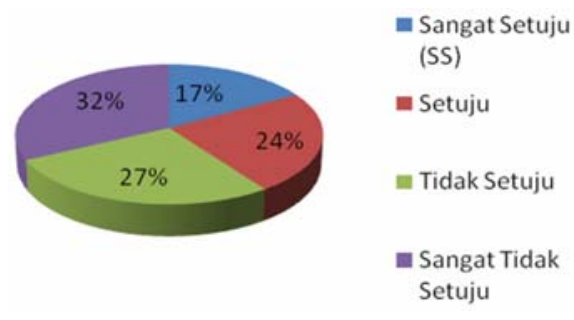

Gambar 9. Grafik accessibility web ujian

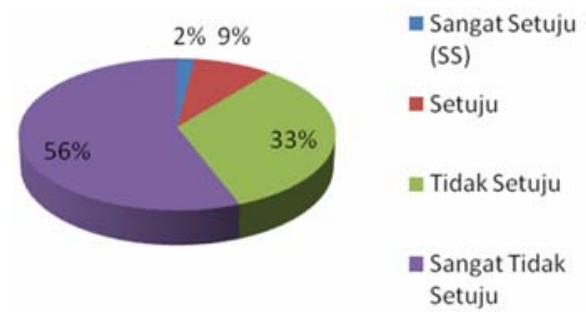

Gambar 8. Grafik availability web ujian

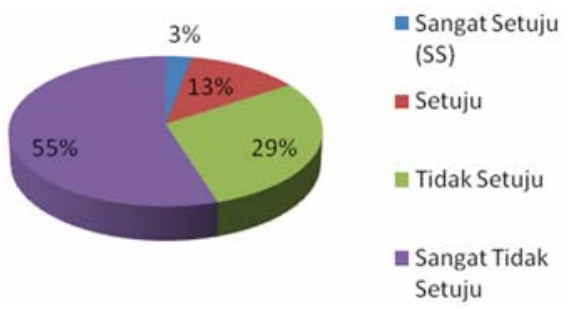

Gambar 10. Grafik time behavior web ujian

guna menyatakan bahwa faktor suitability tidak memenuhi apa yang mereka butuhkan ketika ingin mengevaluasi jwaban yang telah mereka kerjakan.

Gambar 8 menunjukkan availability seringnya terjadi error ketika pengguna akan login masuk kedalam website, membuat pengguna menyatakan bahwa website ujian belum memiliki kualitas yang baik karena aplikasi tidak stabil dan sering terjadi error. Dari hasil analisis database, ditemukan penyebab dari error tersebut.

Rancangan database yang tidak menggunakan relasi, dapat menyebabkan performa sistem berkurang. Query yang dijalankan membutuhkan waktu yang lebih lama ketika tidak ada relasi. Selain itu, faktor indexing juga mempengaruhi faktor availability ini. Dengan diterapkannya indexing, kualitas kecepatan dan ketersediaan aplikasi website ujian dapat meningkat.

Gambar 9 menunjukkan accessibility pengguna menyatakan bahwa aplikasi kurang cepat dalam merespon aktivitas mereka. Hal ini dapat disebabkan oleh tidak maksimalnya fungsi database. Oleh karena itu seperti pembahasan pada grafik sebelumnya, database yang dirancangan dengan relasi dan indexing dapat meningkatkan performa kecepatan dan kehandalan dalam sebuah website.

Gambar 10 menunjukkan time behaviour dengan diterapkannya ujian berbasis web, diharapkan dapat mengoptimalkan peserta ujian dalam melaksanakan ujian. Tetapi pada variabel ini, terlihat jelas bahwa pengguna/peserta ujian menyatakan bahwa sistem yang telah dibuat ini tidak membantu mereka dalam mengoptimalkan ujian. Ba- 
TABEL 2

\begin{tabular}{lcccc}
\multicolumn{4}{c}{ PEMETAAN HASIL KUESIONER POST-TEST } \\
\hline Variabel & $\begin{array}{l}\text { Sangat } \\
\text { Setuju }\end{array}$ & Setuju & $\begin{array}{l}\text { Tidak } \\
\text { Setuju }\end{array}$ & $\begin{array}{l}\text { Sangat } \\
\text { Tidak } \\
\text { Setuju }\end{array}$ \\
\hline $\begin{array}{l}\text { Interface } \\
\text { Attractiveness }\end{array}$ & $31 \%$ & $45 \%$ & $14 \%$ & $10 \%$ \\
Operability & $40 \%$ & $39 \%$ & $15 \%$ & $6 \%$ \\
Understandability & $35 \%$ & $37 \%$ & $20 \%$ & $8 \%$ \\
Navigation & $30 \%$ & $37 \%$ & $22 \%$ & $12 \%$ \\
Suitability & $35 \%$ & $46 \%$ & $11 \%$ & $8 \%$ \\
Availability & $51 \%$ & $40 \%$ & $6 \%$ & $3 \%$ \\
Accessibility & $31 \%$ & $45 \%$ & $14 \%$ & $10 \%$ \\
Time Behavior & $40 \%$ & $39 \%$ & $15 \%$ & $6 \%$ \\
\hline \hline
\end{tabular}

hkan menjadi kendala dalam pengerjaan ujian.

Perancangan prototype untuk memperbaiki user interface yang diterapkan pada website ujian ditunjukkan pada Lampiran Gambar I, telah dibuat berdasarkan metode pengembangan spiral. Kalimat informasi sisa waktu anda yang tertera seperti pada Lampiran Gambar I, tidak menimbulkan perbedaan makna. Sehingga peserta ujian dapat langsung mengerti ketika pertama kali melihat tulisan tesebut pada halaman website ujian. Selain itu diberikan gradasi warna yang berbeda agar terlihat kontras dan menarik perhatian peserta ujian karena sisa waktu ujian merupakan bagian yang penting dalam berlangsungnya sebuah ujian.

Tombol navigasi untuk melanjutkan ke soal berikutnya sudah terlihat jelas pada desain ini. Sehingga mempermudah pengguna dalam mencari tombol navigasi yang user friendly. Pada halaman ini ditambahkan tombol 'Data Soal' yang berfungsi untuk mengevaluasi jawaban yang telah dikerjakan. Akan dibahas lebih lanjut pada bagian halaman data soal.

Lampiran Gambar II menunjukkan halaman data soal ini merupakan halaman tambahan yang dibuat khu-sus untuk mempermudah peserta ujian dalam me-lakukan ujian di Perumnas. Halaman ini berfungsi untuk mengecek kembali jawaban peserta ujian secara keseluruhan. Apabila ada soalyang terlewati atau sengaja akan dijawab pada akhir waktu ujian, pengguna dapat dengan mudah untuk mengecek soal nomer berapa yang belum dijawab. Di hala-man data soal, setelah peserta ujian memilih button pada nomer soal yang belum dijawab, peserta dapat mengubah jawaban dengan menekan tombol ubah jawaban.

Setelah melalui proses prototyping, responden akan diberikan kesempatan untuk mencoba desain yang terbaru. Sehingga responden dapat mengisi kuesioner sesuai dengan hasil prototyping. Untuk variabel pertanyaan kuesioner post-test, butir pertanyaan yang diberikan sama dengan kuesioner pre-test, hanya saja disesuikan untuk variable yang digunakan. Kuesioner post-test tidak menggunakan variabel reliability dan accessibility, dikarenakan prototyping tidak disambungkan ke dalam jaringan Perumnas. Dari hasil kuesioner post-test terlihat jelas prototyping yang dibuat telah memenuhi kriteria dari kualitas sebuah website. Responden setuju bahwa desain user interface pada prototyping lebih baik daripada desain sebelumnya, hal ini dapat dilihat pada Tabel 2 .

\section{Kesimpulan}

Pada penelitian ini, website ujian telah dievaluasi berdasarkan website quality evaluation method. Hasil yang didapatkan yaitu kualitas webstie ujian belum baik. Oleh karena itu dibuatlah prototipe sebagai solusi dan rekomendasi untuk pengembangan website selanjutnya. Selain itu diusulkan juga untuk melakukan perbaikan dalam database.

Hasil prototipe yang dirancang memiliki fitur baru yang berfungsi untuk mempermudah peserta ujian untuk mengevaluasi kembali jawaban mereka bila ada yang terlewat atau ada yang salah dalam menjawab. Dengan fitur baru ini, pengguna dapat dengan leluasa untuk memaksimalkan waktu ujian yang tersedia, juga memaksimalkan nilai mereka dengan cara mengevaluasi kembali sebelum jawana mereka dikirim.

Dari 2 kuesioner yang diberikan pada saat sebelum dan sesudah dibuatnya prototipe, terlihat bahwa dengan user interface yang baru yang ada pada prototipe, kualitas website yang ditinjau dari sisi pengguna dapat meningkat jadi lebih baik.

\section{Referensi}

[1] Schneberger, Scott. (2008). "Factors That Influence the Performance of Combuter- Based Assessments: An Extension of The Technology Acceptance Model". The Journal of Computer Information Systems. 74.

[2] Behkamal, Behshid. (2009). Customizing ISO 9126 quality model for evaluation of B2B applications. Information and Software Technology 51 pg 599-609.

[3] Schramm, J. (2006). "HR Technology competencies: New roles for HR professional", SHRM Research Quaterly, 1, 2-10.

[4] Komang, Setemen (2010). "PENGEMBANGAN EVALUASI PEMBELAJARAN ONLINE". Jurnal Pendidikan dan Pengajaran, Jilid 43, Nomor 3, Oktober 208 2010, hlm. 207-214.

[5] Schneberger, Scott. (2008). "Factors That Influence the Performance of Combuter-Based Assessments: An Extension of The Technology Acceptance Model". The Journal of Computer Information Systems. 74.

[6] Luis Olsina, e. a. (2002). Book Web Quality. Springer, 10.1007/3-540-28218-1_4, Pages 109-142. 
[7] Nabil, Doaa. (2011). Web-Based Applications quality factors: A survey and a proposed conceptual model. Egyptian Informatics Journal (2011) 12, 211-217.

[8] Singh, Kavindra Kumar. (2014). Implementation of a Model for Websites Quality Evaluation-DU Website. International Journal of Innovations \& Advancement in Computer Science. Volume 3, Issue 1.
[9] Passig, David. (2009). Structural and conceptual user interfaces and their impact onlearning. Springer, 15:51-66.

[10] Chang S. Nam. (2007). Web-Based Learning Environment: A Theory-Based Design Process for Development and Evaluation. Journal of Information Technology Education. Volume 6.

\section{Lampiran}

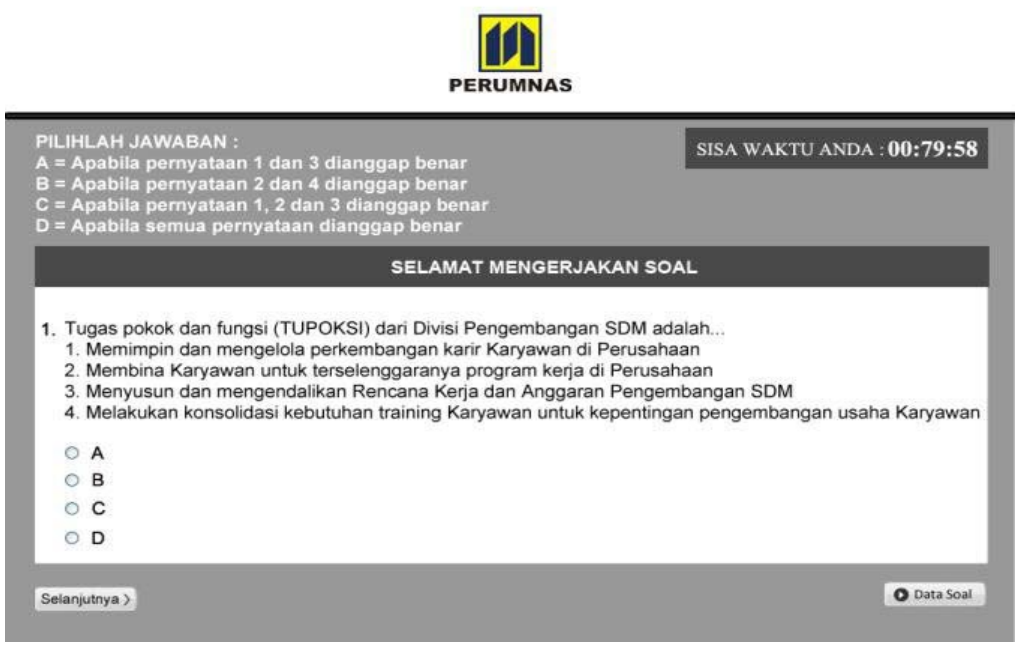

Lampiran Gambar I. Gambar prototipe halaman soal ujian

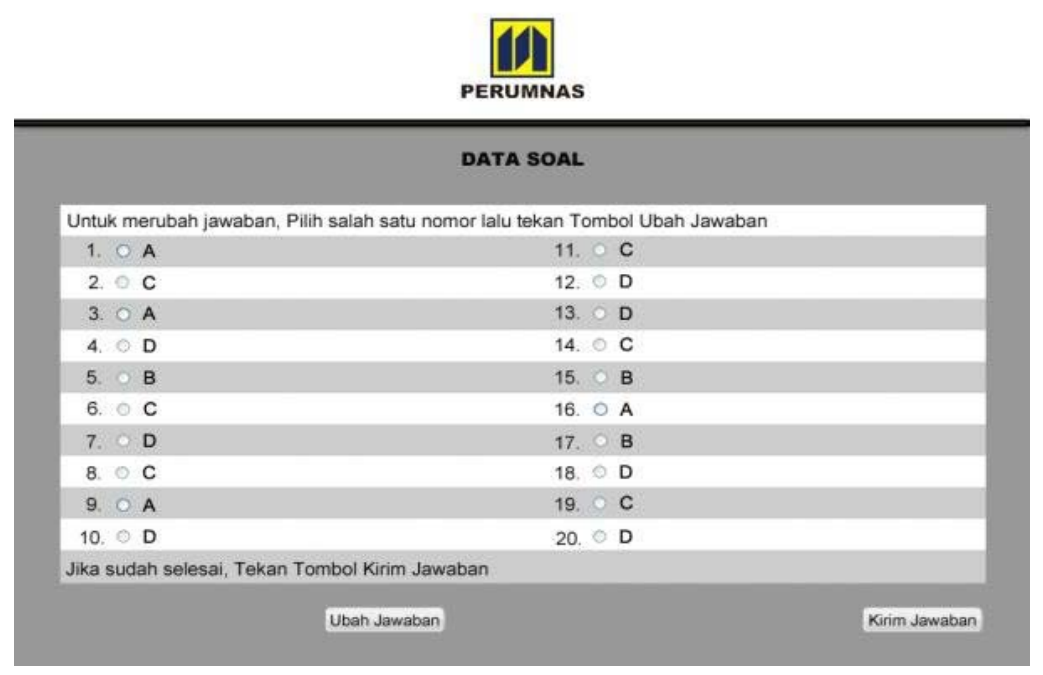

Lampiran Gambar II. Gambar prototipe halaman data soal 